\title{
Editorial: The Struggle for Equity: Rights, food sovereignty and the rethinking of modernity
}

\author{
STEFANO PRATO
}

'An imbalance between rich and poor is the oldest and most fatal ailment of all republics' Plutarch, ancient Greek biographer (c. 46-120 CE)

Disparities between the rich and the poor are not an element of novelty, as the quote from Plutarch reminds us. However, inequalities have been somehow peripheral to the development discourse and have only recaptured the attention of the development community in recent years. Indeed, the significant increase of disparities across economic, social, political and intergenerational domains, and the consequent concentration of wealth in fewer hands, has characterized the recent growth and development patterns of most countries, irrespectively of conventional distinctions between North and South. Some have suggested that inequalities are a distinctive feature of modern societies, contributing to the silent emergence of their social acceptance as an intrinsic characteristic of modernity.

Inclusion and equity are probably two among the framing issues of our times and many voices are loudly advocating for these to become the central pillars of the development agenda. Interestingly, inequalities are a global phenomenon. It is the first time in modern history that one common concern appears to be so deeply shared by the poor and marginalized as well as struggling middle classes across the entire globe. Some identify in the proliferation of 'occupy-type' movements and the rise in global protests the early signs of what might possibly become a new global class warfare, something that has the potential of profoundly destabilizing societies and economies. Indeed, there is something about inequalities - a sort of a deep, shared aversion to unfairness - that is powerful and seems to generate an even stronger visceral reaction than poverty per se.

\section{Conceptual framework}

Income inequalities have often polarized attention and been used as the proxy for framing the debate. However, it is essential to conceptualize inequalities in a much broader manner and recognize that they span across multiple domains (i.e., the areas in which they manifest themselves: political, social, economic) and lines of fracture (i.e., different social divisions along which they stratify: horizontal, vertical, spatial and intergenerational), as shown in Figure 1. 


\section{Development 57(3-4): Upfront}
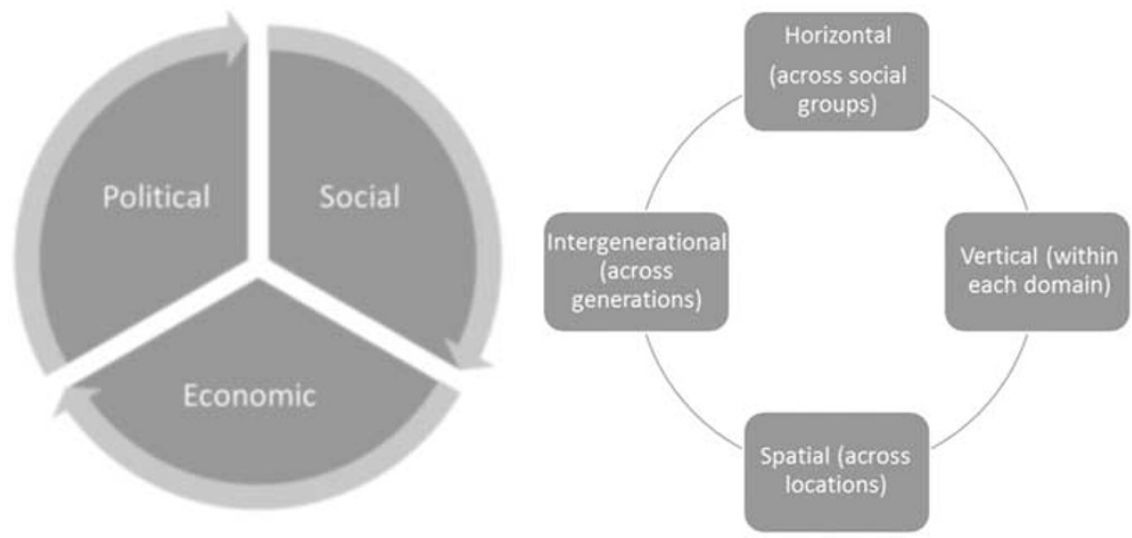

Figure 1: The multiple domains and dimensions of inequalities

Moving from a unidimensional analysis of inequalities (i.e., the one focused on income) to a multidimensional one exposes the evidence that some social groups and some geographic locations are more likely to suffer multiple inequalities, hence highlighting the existence of power structures within society. Indeed, an analysis of power structures and the unveiling of the political economy of inequalities are essential pillars of the inclusion and equity analytical framework.

The British economist and political theorist Harold Laski (1893-1950) affirmed: 'A State divided into a small number of rich and a large number of poor will always develop a government manipulated by the rich to protect the amenities represented by their property'. Inequalities are reinforced by the capture of the policy space by the wealthy and the use of law as an instrument of power rather than justice. Political economies are increasingly evident in many policy decisions as well as in the way public resources are generated and allocated.

There are three distinct, though closely interconnected, spheres of the inequality approach. The first and most common is descriptive. It focuses on demystifying averages and finding new approaches to describe reality that highlights disparities in distribution. Data disaggregation by gender, age and different social groups (leading to an analysis of horizontal inequalities) as well as by location (leading to spatial assessment of inequalities) are the most notable examples of this approach. How312 ever, vertical analyses tend to be limited to the income and sometimes wealth domains, though increasingly work is being advanced to compare qualitative disparities in access to social services between the rich and the poor. At the aggregate level, many advocate for a shift from per capita figures or averages (considered of limited significance when distribution is significantly skewed) to distributional-sensitive measures such as the median. ${ }^{1}$ Many also support the replacement of the Gini indicator, relatively obscure in design and significance, to the immediateness and greater sensitivity of the Palma indicator, which is the income share of the top 10 percent divided by the income share of the poorest 40 percent. Therefore, the descriptive approach to inequalities is steadily advancing and indeed changing the way in which reality is presented and progress is monitored. The downside of this approach is the promotion of a further technocratic shift in development monitoring and accountability that is based on numbers rather than on the direct participation of those primarily affected by development challenges. While data helps, it should be its subjective assessment, rather than a bunch of statistics, the primary source of monitoring of development progress.

The second sphere is analytical. It exposes the relation between the two tails of the distribution and the nexus between exclusion and marginalization, on one side, and prosperity on the other. This is where the real novelty of the inequality analysis lies and is a significant departure from an 
approach exclusively focused on poverty. Taken within an African context for instance, it immediately exposes the morally unacceptable 'necessity' of poverty for the continued exploitation of cheap labour, the grabbing of land and other resources, and the persistence of formal democracies based on mass populism. However, one of the main attempts to domesticate the inequality framework is to reduce it to the poverty approach, by simply changing taxonomy without altering the substance of the discourse. It is therefore essential to highlight the conceptual differences between the inequality and the poverty approaches. First, the latter has consistently focused on one side of the (income) distribution and social stratification. It has focused on people crossing a line, regardless of how it was defined. Whether it is the international income poverty line, national poverty lines or even a multi-dimensional poverty index, the poverty approach concentrates on moving people from a place where they are defined as 'being poor' to one where they are no longer 'poor'. Conversely, the inequality approach focuses on the entire spread and explicitly connects poverty with prosperity as it highlights the relations between both tails of the distribution with the objective of reducing the distance between the two. Second, the conventional poverty approach has tended to leave the drivers of marginalization unchallenged, even if many researchers and policy players have focused extensively on them. It tended to focus on inclusion (crossing the line) without analyzing the terms of such inclusion (i.e., plantation workers are considered included even if the terms of their inclusion are inequitable). A multidimensional inequality framework fundamentally interrogates the terms of inclusion and thus addresses both inclusion and equity. It is therefore implicitly transformational. Thirdly, poverty approaches tended to focus of those defined as 'poor' or 'losers', often undermining human dignity with such characterizations. An inequality-driven perspective focuses on both the winners and losers, forcing a political economy analysis that highlights how the status quo has its owners and supporting power structures. Lastly, poverty approaches have been dominated by the search for 'objective' measurements. As mentioned above, they defined people as 'poor' and defined when they would no longer be poor. The inequality analysis gives people a gender, a social affiliation, a location. It demystifies the averages and gives everyone his/her human face and dignity. It forces a subjective analysis of fairness that cannot be reduced to a simple number, even if numbers help. It imposes a combination of objective and subjective measurements of progress and thus highlights the importance of people's subjective judgement of their equitable treatment.

The third sphere is normative. It involves programmes, policies and legislative interventions aimed at tackling inequalities and re-aligning current realities to more equitable standards and conditions. It therefore calls for profound transformations in the social, economic and political domains. This is where the attempts to domesticate the inequality framework, by reducing it to a refreshed poverty approach, have been particularly effective. First, conventional approaches to address inequalities have been primarily aimed at promoting inclusion rather than equity, just a more sophisticated way to define the poverty line. As described in the graphics of Figure 2 below, ${ }^{2}$ many development interventions, while often well intended, result in some sort of a 'social bribery' where those at the margins are provided with basic social services (vaccinations, primary education, etc.) and modest increases in income. These modest improvements keep them afloat without changing their fundamental lack of access to lifechanging opportunities or the current power dynamics. They are given the impression that their lane is moving, while in fact it is advancing at a much slower pace than others, and the gap between them and the wealthy is widening. But the social bribery does not stop there. Not only are the terms of inclusion inequitable. They trap people on the margins of a society and in an economy dominated by the wealthy in which they have no place and no say. The ongoing attempts to engage and attach small-holders to the lower end of regional and global value chains, where they are diverted from their traditional markets and production methods and increasingly squeezed between the rising costs of agricultural inputs and wholesale purchasing prices provides a perfect example. An equity-centred normative approach 


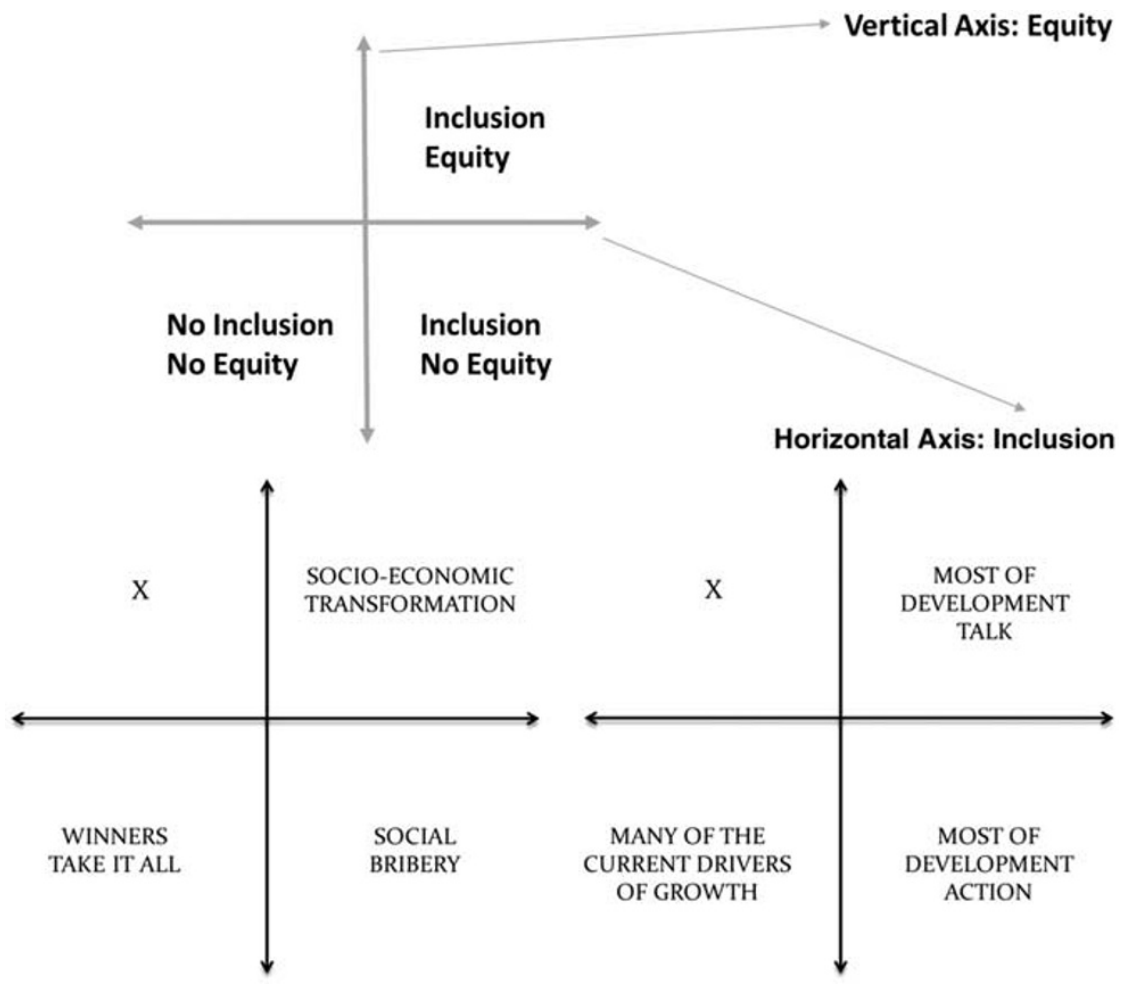

Figure 2: SID's State of East Africa Report Equity-Inclusion Nexus

to tackling inequalities needs to rise above these disempowering interpretations and be able to challenge existing power structures and development strategies.

\section{The fallacy of the 'inclusive growth' concept}

The inclusive growth narrative, with its glaring omission of the challenges of commodity-dependent developing countries and benign characterizations of trade and global value chains, is a perfect example of the often-malicious attempt to interchangeably use the terms 'inclusion' and 'equity'. It is a well-crafted narrative masking the intent to leave fundamentally unchanged the terms of inclusion with very uneven power relations and inequitable economic and social outcomes. This state of affairs highlights the lack of 314 due consideration for the political economy of inequalities, as these are being often referred to as some sort of 'natural outcome' which at best requires mitigation rather than the result of deliberate policies of exclusion and exploitation.

The search for equity inevitably involves profound changes in power relations that current power holders have limited interest in stewarding. Hence, the complexity of this agenda and the overt and covert attempts to frame it in more friendly terms for those in power.

\section{Tackling inequalities is a governance question}

It is evident that the persistence and even increase of current inequalities is the manifestation of significant democratic deficits maintained through ossified power structures. This is the reason why the inequality question is fundamentally a governance issue rather than one of economic and social 
policy as it requires an overarching policy inclination to build more egalitarian and equitable societies and economies, which will then percolate down to multiple policy domains.

Indeed, inequalities impose an analytical framework that exposes the close nexus between poverty and prosperity and highlights how the current pattern of growth thrives on marginalization and inequitable inclusion. When assessing the political economy of exclusion, government and intergovernmental agencies are often significantly constrained by formal and informal mechanisms that award wins to existing power structures. The role of civil society in advancing the fight against these political economies (though some of its segments are not immune to the 'disease' having been cooped in multistakeholder mechanisms) is critical for its direct action, its civil mobilization and its capacity to offer anchor to those within formal institutions that are keen to advance social change. It should therefore not be surprising that many governments, particularly in developing countries, but not only, are pursuing deliberate efforts to limit the democratic space and undermine civil society capacity and areas of operations. Even when government action is legitimate and deliberate in addressing the transformative question, there is a serious limitation of policy space under the existing framework of hegemonic economic globalization and liberalization. This is particularly evident in the African context, where it is therefore hardly possible to discuss socio-economic transformation of the region without addressing the drivers that reproduce global inequalities and relegate Africa to the provider of primary commodities and minerals.

\section{The corporate theory of change at play}

Advancing a normative agenda to tackle inequalities and promote equity means confronting the corporate theory of change currently at play, one based on the following seven pillars (any intuitive parallelism with the seven sins left aside):

- The commodification of life and the human body, with the continued enlargement of the scope of marketable and tradable goods (knowledge, education, health, water, seeds and genetic resources, etc.).

- An increasingly hegemonic and homogenizing form of economic globalization, with transnational corporations, increasingly merging into huge conglomerates and promoting the same brands and products across the globe, in the driving seat.

- The co-option of science, often supported by new forms of philantrocapitalism, to support the global narrative and provide new technological instruments to advance commodification and globalization (i.e., the new genetic research and the dematerialization of genetic resources).

- The continued loss of national sovereignty through international agreements (multilateral, plurilateral and bilateral) that promote extreme forms of economic liberalism, ossify power relations, promote unsustainable production and consumption patterns in the name of global value chains, maximize the disconnect between contiguous territories, subordinate human rights to the market, and promote 'financialization'.

- The continued reduction, if not progressive abdication, of the developmental role of the State, despite the fanfare of the new global development agenda, with the State increasingly depicted as 'one actor among many' with limited resources to be increasingly used to leverage and catalyze private sector engagement and public-private partnerships.

- A shrinking democratic space, despite the claimed advancement of liberal democracies, through token forms of public consultation, the continued de-structuring of the structures of dissent, the weakening of free media and independent policy analysis, increased surveillance of all communications and the veiled implication of pre-emptive control and the tightening of rules of operations and foreign financing on civil society organizations.

- The capture of public policy by large corporations (moving from behind the scene actors to fully legitimized ones) through the shifting of governance from sovereign spaces to largely unaccountable multistakeholder platforms that blur the lines between public and private 
interest and respond to stakeholders rather than rights-holders.

Interestingly, the new 2030 Sustainable Development Agenda is far from being immune from this theory of change and may as well become another powerful instrument at its service. Indeed, the entire negotiation process was characterized by the pervasive influence of the corporate sector, the unjustified confidence in the role of the private sector, without any advancement in the muchneeded reformulation of the current business model, and significant bias in favour of multistakeholder platforms and private sector-led implementation. This was further confirmed by the regressive nature of the Addis Ababa Action Agenda, the outcome of the Third Financing for Development Conference, which failed to deliver any meaningful advancement in the much-needed democratization of global economic governance, as denounced by the global civil society platform that followed the process. ${ }^{3}$

\section{Strengthening a people-centred agenda}

Against such powerful theory of change, how can a countervailing people-centred agenda for social justice, equity, ecology and respect for diversity be strengthened?

The first pillar is the recognition and reaffirmation of the centrality and indivisibility of human rights. This is unfortunately becoming more of an uphill struggle. By refusing to ground its key components in a firm human rights framework, the new 2030 Sustainable Development agenda promotes the backward shift of rights into needs and opens the way for their provision through market mechanisms rather than the duty-bearer role of the State. This translates into the pervasive privatization of public services and the promotion of public-private partnerships, despite the increasing evidence that shows that they alter the nature of public services and investments, worsen the fiscal problems they were supposed to solve, expose fundamental faults in transparency and democratic accountability, and provide less efficient and more costly operations than they 316 claim.
The recently launched Right to Food and Nutrition Watch $2015^{4}$ on 'People's Nutrition is Not a Business' clearly illustrates 'how the increasing control of businesses over food systems and resources, institutions, policy spaces and governance structures, is putting human rights at great risk' and undermines the capacity for national governments to fulfil their human rights obligations, including the right to adequate food and nutrition.

At a higher level of analysis, it is important to recognize that the rights of citizens have been at the core of modern constitutionalism and the basis of the legitimacy of the State. As Sofia Monsalve of FIAN International brilliantly articulated at the recently concluded Forty-Second Session of the Committee of World Food Security, the shift from rights to needs is the first step in the dissolution of the modern State and the return of a neo-feudal system based on the governance of the powerful with (some) moral ethics. This would mark the extension of the corporate social responsibility approach to governance and the renewed spin from justice to charity. Hence, the need to reclaim public spaces, at all levels of governance, protect them from the undue influence of private interests, and ensure that they respond to rights holders.

The second pillar involves the need to rethink modernity in all its dimensions, rather than persist on pursuing a development agenda based on extending the current unsustainable model of production and consumption. In this respect, it is essential to join forces to strengthen peoples' movements that celebrate diversity and promote the cohabitation of diverse worldviews and nonwestern visions for a holistic and convivial development, learning from the world's indigenous peoples struggles for autonomy and livelihoods in Latin America and elsewhere. ${ }^{5}$

However, cohabitation with a predatory and hegemonic form of economic globalization is hardly possible. Hence, the third pillar is based on resistance to the current dynamics and strengthening of alternative social, economic and political frameworks. This is where food sovereignty and the strengthening of local food systems based on agroecology offers a powerful pathway. Citing the Declaration of Nyéléni 2015: ${ }^{6}$ 
Agroecology is the answer to how to transform and repair our material reality in a food system and rural world that has been devastated by industrial food production and its so called Green and Blue Revolutions. We see Agroecology as a key form of resistance to an economic system that puts profit before life

The corporate model over-produces food that poisons us, destroys soil fertility, is responsible for the deforestation of rural areas, the contamination of water and the acidification of oceans and killing of fisheries. Essential natural resources have been commodified, and rising production costs are driving us off the land. Farmers' seeds are being stolen and sold back to us at exorbitant prices, bred as varieties that depend on costly, contaminating agrochemicals. The industrial food system is a key driver of the multiple crises of climate, food, environmental, public health and others. Free trade and corporate investment agreements, Investor-State Dispute Settlement agreements, and false solutions such as carbon markets, and the growing 'financialization' of land and food, etc., all further aggravate these crises. Agroecology within a Food Sovereignty framework offers us a collective path forward from these crises.

Building on the spirit of the Declaration of Nyéléni, the fourth pillar is related to the question of agency. The construction of such a peoplecentred agenda for social justice, equity, ecology, and respect for diversity can only be driven by the inspiration and leadership of social movements and the direct participation of those most affected by development challenges. This can often contrast sharply with the increased professionalization of non-governmental organizations and their increasing attachment to mainstream agendas. The decisive test of their commitment to equity and social justice will indeed be their availability and capacity to step aside and place their agency and resources at the service of an agenda led by the movements that are the direct expression by those primarily affected by marginalization and inequalities. Failing to do so, they will end becoming a significant part of the problem they claim to address.

However, there also needs to be some reflection on how movements and civil society organization, assuming they manage to coalesce, need to organize in order to meet current and future challenges. True they may offer alternative paths, but it remains intrinsic to their nature that these will not be the only paths, on both sides of the political spectrum. As they consolidate and coalesce, there will emerge a different set of movements to the left of the coalescing group that would claim to be more authentic and would exercise wedge pressure to the unity of the movement. Organizing and resisting in the time of Orwell's fantasies (we are in post-1984) also means that critical mass will be harder to attain and the means and methods of resistance will suffer literal adaptations in some places with potentially critical consequences overall. This may particularly happen in those countries that perhaps have a greater need to unravel their current political and economic systems.

However, the greatest challenge would probably be that of awakening public consciousness in a period when people are bombarded by millions of messages of dubious, often contradictory intent. How to move beyond the 'converted' and capture new converts? The confident feeling of self-righteousness and the truth/correctness of the messages might be helpful in the corridors of the faithful, but they are not necessarily helpful in winning new converts or conquering new ground among the undecided. There is indeed a huge mass of agnostic indifferent consumers, who are not concerned with the ecological limits of the planet and/or the injustices that went into producing the gadgets they apparently cannot live without. How should the gap between their 'needs' and the lived experiences on the other side be narrowed? Until this happens, until people are willing to sacrifice their material comforts for a better world in the vision that runs counter to that of today's corporate spin-doctors, there is limited room for change because far too many will tend to favour status quo and its imperfection. Sadly, too many within the precarious middle classes fall into this camp. The fundamental challenge then might be not so much that of pushing power and power structures as it is educating and challenging privileged citizens and consumers to change their habits and make the connection between their comforts and other people's misery. The inequality framework has the ambition to promote a first modest step in this direction. 


\section{In this journal issue}

This double issue of Development addresses many of the issues and challenges described above. The Upfront Section opens with the Accra Declaration, the political statement of the Africa-wide Conference on 'Tackling Inequalities in the context of Structural Transformation' (Accra, Ghana, April 2014), a major source of inspiration and content of this journal issue. Guest Editor Alex Cobham explains the current patterns of 'counting' can both reflect and exacerbate existing inequalities, and explores the likely obstacles and the unaddressed weaknesses the 2030 Sustainable Development Agenda. On the other hand, Chief Justice of Kenya Willy Mutunga claims that the crisis faced by many countries in governance and development is the crisis of the elite, and its rather grotesque inversion of values.

The Thematic Section addresses key dimensions of the inequality question. Frances Stewart frames the debate and explores the relationships between inequality and economic, political and environmental sustainability, arguing that reductions in inequality would contribute to all three types of sustainability. Ashish Kothari, Federico Demaria and Alberto Acosta challenge the conventional Sustainable Development and Green Economy paradigms and explore the alternative visions and politics inspired by Buen Vivir, Degrowth and Ecological Swaraj. Nora Lustig addresses, from a Latin American perspective, the role of social spending and taxation in promoting income redistribution and achieving development goals. Several authors (Cheryl R. Doss, Carmen Diana Deere, Abena D. Oduro and Hema Swaminathan, Nidhi Tandon and Melinda Vandenbeld Giles) explore various dimensions of the quest for gender equality and present a gender analysis of income, asset and wealth gaps. Grace Kite, José Manuel Roche and Lisa Wise offer concrete methodologies to incentivize equitable progress through data disaggregation and the setting of interim targets. Tessa Khan interrogates the new wave of Preferential Trade Agreements and their impact on human rights and inequalities. Elizabeth Lockwood and Rachele Tardi address the critical issue of the inclusion of persons with disabilities in the implementation of the 2030 Agenda for Sustainable Development.

Inspired by the Accra conference, the Dialogue Section focuses on the quest to tackle African inequalities in the context of structural transformation. It is opened by a framing piece by Bartholomew Armah, Mama Keita, Aissatou Gueye, Valerio Bosco, Judith Ameso and Zivanemoyo Chinzara, addressing the role of active government policies in pursuing structural transformation in the region. Iris Macculi and Carlos Acosta Bermúdez present the African Social Development Index as a key policy instrument aimed at reducing human exclusion within the structural transformation agenda. Bernadette M. Wanjala builds further on the issue of gendered asset inequalities from a particular African perspective. Louis Kasekende explores the role played by financial inclusion within the policy agenda for inclusive growth in sub-Saharan Africa. Abdul-Gafaru Abdulai outlines the politics of resource sharing and regional inequality in Ghana and draws lessons for the new development agenda.

The Local/Global Encounters Section features a set of African case studies, most of which were developed in the context of the above mentioned African-wide Conference on 'Tackling Inequalities in the context of Structural Transformation': South Africa (two different articles by Pali Lehohla and Nozipho Shabalala, and Babatunde Omilola and Olusegun A. Akanbi, respectively), Ethiopia (Abbi M. Kedir), Ghana (Eric Osei-Assibey), Nigeria (Ademola Ariyo and Olanrewaju Olaniyan), Senegal (Mbaye Diene), Kenya (Jeremiah Owiti), Mauritius (Sheila Bunwaree), Tanzania (Edmund Matotay) and Uganda (Charles Lwanga-Ntale). The country case studies are complemented by two articles exploring the issue of inequality from the particular perspective of HIV and AIDS, looking at South Africa (Charl Swart and Pieter Fourie) and Egypt (Ahmed W. Elroukh and James A. Thornton). 


\section{Notes}

1 The median is the number separating the higher half of each data sample from the lower half, that is, the median income is the amount that divides the income distribution into two equal groups, half having income above that amount and half having income below that amount.

2 Taken from the SID's State of East Africa Report 2013, a report published annually by SID on the state of East Africa, http://soea.sidint.net/reports/ (last visited on 19 October 2015).

3 See the 'Third FfD Failing to Finance Development', the Civil Society's response to the Addis Ababa Action Agenda on Financing for Development, https://csoforffd.files.wordpress.com/2015/07/cso-response-to-ffd-addis-ababaaction-agenda-16-july-2015.pdf (last visited on 19 October 2015).

4 The Right to Food and Nutrition Watch is published annually by a consortium of organizations led by FIAN International, Bread for the World and the Interchurch Organization for Development Cooperation (ICCO). It can be found at http://www.rtfn-watch.org/fileadmin/media/rtfn-watch.org/ENGLISH/pdf/Watch_2015/RtFNWatch_ EN_web.pdf (last visited on 19 October 2015).

5 Please also read Development Journal on Cosmovisions (Volume 54, Issue 4).

6 Declaration of the International Forum for Agroecology, Nyéléni, Mali, 27 February 2015. Please visit at http:// www.foodsovereignty.org/forum-agroecology-nyeleni-2015/ (last visited on 19 October 2015). 